\title{
The role of critical motivation in the development of altruistic behaviour in youth
}

\author{
Gabriela Monica Assante •, Mariana Momanu•
}

\begin{abstract}
The main objective of this study is to investigate the relationship between critical motivation, altruism and peer caring as the moral foundation of social life. Although the direct relationship between critical consciousness and prosocial involvement has for some time entered the realm of educational research, the mechanisms by which the components of critical consciousness influence behaviour are not clearly defined. Therefore, we investigated the mediating role of the tendency to protect others as a moral foundation in the relationship between critical motivation and altruistic behaviour. The study involved 308 young people aged 18-24. Participants were recruited from various urban high schools and universities, and invited to complete a set of questionnaires. The results emphasise the importance of critical motivation as a predictor of altruistic behaviour. Moreover, the data indicate that the tendency to protect others mediated the effects of critical motivation regarding altruistic behaviour. These results provide a clearer perspective on the process by which critical motivation can influence the behaviour and involvement of young people in different social contexts. The results emphasise especially the importance of developing and stimulating critical motivation in schools in order to increase the active involvement of young people in the current social context.
\end{abstract}

Keywords: critical consciousness; critical motivation; youth; altruistic behaviour; moral foundation

\section{Introduction}

The views and beliefs of youth provide a unique standpoint from which social change processes can be observed. The provided perspective facilitates the examination of various social theories and provides insight over the social order (Shildrick, Blackman \& MacDonald, 2009; Furlong \& Cartmel, 2007). These aspects must receive significant consideration as they reflect the future behaviour of young adults specific to the investigated social context. Young people represent a group of active citizens that should be playing a role in all areas of the community. They are important resources in any social

\footnotetext{
- Assistant Professor, PhD, Educational Sciences Department, Alexandru Ioan Cuza University, Iași, Romania, correspondence author: monica.assante@uaic.ro

- Professor, Educational Sciences Department, Alexandru Ioan Cuza University, Iași, Romania, momanu@uaic.ro
} 
environment whose development must be encouraged in any continuously developing society (Finn \& Checkoway, 1998).

As capable citizens, youth can participate in the decision-making process that impacts their everyday reality. Therefore, developing the responsibility to participate in community life is required to promote civic engagement behaviours of community members. Young people can act as primary actors in addressing the social inequity issues and other social predicaments present in their social realities by cultivating critical inquiry and leadership skills and applying them in their communities (Hancock, 1994).

Based on Freire's conceptualisation, critical consciousness points to the following fundamental components: critical reflection, critical motivation and critical action. Critical consciousness refers to how individuals critically reflect on their social reality and are actively involved in the decision-making process, which can generate positive changes in various social contexts. Although critical consciousness includes various components, such as critical reflection, critical motivation and critical action, the latter was shown to impact the involvement of the individual in social life, especially in promoting equality and equity as civic values (Ginwright \& James, 2002). The onset of critical consciousness is strongly determined by the development of young people's ability to reflect on various aspects of social life and to develop their motivation to change unfavourable social conditions in the various contexts that family, school, and society offer young people (Freire, 1973; Giroux, 1983; Flanagan et al, 2007). In addition, how teachers relate to the issue of social life through an honest, open and flexible approach that values multiple perspectives and critical thinking to encourage the formation of their own opinions through democratic dialogue, plays a decisive role in developing students' critical awareness and motivation to become involved in the process of positive social change (Youniss \& Yates, 1997; Kirshner, 2009).

In Critical Consciousness Theory anchored in freirean thought (Freire, 2005), all three core elements hold a specific role because critical consciousness represents a process during which the individual learns to identify social, political and economic disparities, and takes action upon those social reality elements that require change. During critical reflection, individuals learn to examine the specific circumstances and social structures that lead to unjust situations for different people. Specifically, it implies a social analysis process and moral dismissal of societal inequities that act as constraints of the individual agency and well-being. Being critically reflective helps build a systemic frame through which people start observing social problems and inequalities. Further, the perceived capability and engagement to address unfairness is attributed to critical motivation. Critical motivation points to the recognised capability to influence social change employing an individual or collective action. The likelihood for people to actively engage in this process is substantially higher if they have the impression that they can determine change (Diemer, Rapa, Voight \& McWhirter, 2016). In turn, critical action relates to people's engagement to change observed injustices. Specifically, this applies to 
the individual or collective action taken against those social aspects, such as institutional policies and practices, considered unjust.

However, at times, critical action may not meet its intentions, which can determine feelings of frustration rather than raise awareness of social predicaments (Watts, Diemer \& Voight, 2011). The central elements of Critical Consciousness Theory (Freire, 2005) are focused on increasing knowledge over social circumstances, promoting critical questioning and cultivating collective identity (Watts \& Hipolito-Delgado, 2015). In general, critical consciousness theories and approaches ordinarily report a blend of critical social analysis, political self-efficacy, collective social identity and actions meant to advance social equity (Watts, Diemer \& Voight, 2011). Therefore, critical consciousness was often regarded as an "antidote" to injustice because it promotes awareness, motivation and action in order to recognise, challenge and improve social and structural restraints (Diemer, Rapa, Voight \& McWhirter, 2016).

There is increasing interest in studying individuals' pro-social behaviour as well as the determinants of altruistic behaviour because it can provide valuable insight into the behaviour of future generations (Marcu \& Bucuță, 2016). Rushton (1982) stated that altruism is a universal value in every human society and concluded that an altruistic type of personality does exist. Later on, however, research surprisingly changed the perspective: altruism is not regarded as a general factor of personality (Rushton, 2008); rather, personality traits are adding to altruist behaviour. This relation differs according to the nature of the relationship between the people involved (Oda et al., 2014). Furthermore, moral values and foundations are connected to commitment to various types of prosocial and altruistic behaviour. Because this type of behaviour increases during adolescence, its development is mainly associated with the development of moral foundations (Lai, Siu \& Shek, 2015). As previously mentioned, critical consciousness aims to raise awareness concerning issues of social equity; however, critical consciousness makes acknowledging equity-related situations easier especially when those biases contrast with youth's moral foundations (Diemer, Rapa, Voight \& McWhirter, 2016; Tyler, 2020). For challenging biases, critical consciousness is also linked to matters of moral reasoning being related to several aspects of the individual's, such as their emotional, moral and spiritual life (Mustakova-Possardt, 2004).

Evidence suggests that critical consciousness in youth is associated with positive outcomes in different areas, such as academic achievement (Godfrey et al., 2019; Seider, Clark \& Graves, 2020) and altruistic and civic behaviour (Hope, 2016; Diemer \& Li, 2011; Diemer \& Rapa, 2016; Diemer \& Blustein, 2006) without fully clarifying the nature of this process. Although previous research on critical consciousness has focused mainly on individuals from marginalised groups (Diemer \& Li, 2011; Chronister \& McWhirter, 2006), recently, the value of investigating critical consciousness for privileged groups while acknowledging the reciprocal relationship between privileged and marginalised has been signalled (Patterson et al., 2021; Godfrey \& Burson, 2018). To acquire social transformation, privileged individuals need to learn to identify social disparities (Jemal, 
2017). This provides a mechanism whereby privileged individuals develop critical consciousness regarding bias against others and later recall the mechanism through which their privilege is preserved through the marginalisation of others (Diemer, Rapa, Voight \& McWhirter, 2016). Although recent studies show that critical consciousness developed by individuals in school may be valuable for supporting social behaviours (Patterson et al., 2021), the question remains as to the relationship between critical consciousness components and social behaviours, such as altruistic behaviour, in privileged individuals. The present study aims to fill this knowledge gap by regarding the relationship between critical consciousness and social action. Acknowledging the importance of moral values in the development of youth social behaviour and critical consciousness, this research also considers the role of caring for others as moral foundation when investigating the relationship between critical consciousness and altruistic behaviour.

\section{The present study}

Recent studies have emphasised the connection between critical consciousness and social behaviour (Patterson et al., 2021; Ajaps \& Obiagu, 2020). Moreover, moral reasoning and moral foundations have been shown to influence social behaviour (Lai, Siu \& Shek, 2015). Nonetheless, the extent of the relationship between critical consciousness components, social behaviour and moral foundations is far from being fully explained. Hence, the main purpose of the present research is to identify the extent of the relationship between critical consciousness components, caring for others and altruistic behaviour in privileged groups of young people. Critical motivation was hypothesised to be good predictor of social behaviour and this relation we believe is mediated by the level of caring for others.

Whereas previous research investigated critical consciousness development in young people while primarily focused on marginalised individuals, the study of these aspects of critical consciousness development on privileged groups might be more informative on how privileged individuals come to recognise social inequalities, which is crucial for acquiring social change (Jemal, 2017).

The hypothesised mediation model is depicted in Fig. 1.

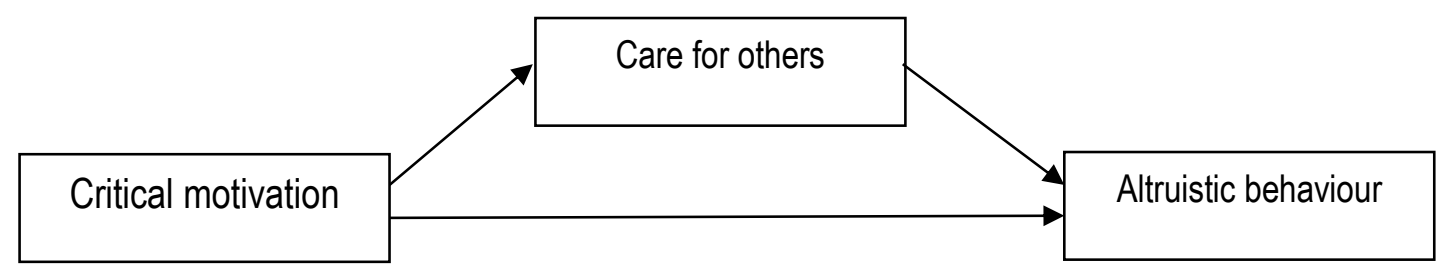

Figure 1. The hypothesized mediational model 


\section{Method}

\section{Procedure}

The participants included in the research were recruited from high schools and universities located in the northeast region of Romania. They have enrolled either in the last year of high school or the first year of their Bachelor's studies. Participation in the study was entirely voluntary although some students received extra credit for their participation. In the case of the high-school students, the minimum age limit was set at 18-years-old. The researcher informed participants about privacy issues such as anonymity, data confidentiality, storage, publication, voluntary participation and about the possibility to withdraw from the study at any time. Every participant signed an informed consent form after receiving the information regarding the study. Due to restrictions caused by the current health crisis, data were collected via self-report questionnaires administered online at the end of the participants' online school sessions. There was no missing information on the measured variables: critical consciousness components, altruistic behaviour and care for others moral foundation. Completing the questionnaire took approximately 20 minutes. The Ethics Committee of Alexandru Ioan Cuza University approved the study and the data were gathered during the first two months of the current year.

\section{Participants}

The study sample consists of 308 participants (mean age $=19.20 ; \mathrm{SD}=1.08$ ). The participants enrolled in the last year of high-school (19.81\%) included 48 female and 13 male participants. Participants enrolled in the first year at university (80.19\%), included 200 female and 47 male participants. An age criterion was included for the selection of high-school students (minimum of 18-years-old). In the case of University participants, they had to be enrolled in their first year of Bachelor's studies (see Table 1).

\begin{tabular}{|c|c|c|c|c|}
\hline $\begin{array}{l}\text { Participants } \\
\text { characteristics }\end{array}$ & $\mathrm{n}$ & $\%$ & $\mathrm{M}$ & SD \\
\hline Age & & & 19.20 & 1.08 \\
\hline \multicolumn{5}{|l|}{ Gender } \\
\hline Female & 248 & $80.5 \%$ & & \\
\hline Male & 60 & $19.5 \%$ & & \\
\hline \multicolumn{5}{|l|}{ School attended } \\
\hline High-school & 61 & $19.8 \%$ & & \\
\hline University & 247 & $80.2 \%$ & & \\
\hline
\end{tabular}




\section{Instruments}

The Critical Consciousness Scale - Short Form (CCS-S) (Rapa, Bolding \& Jamil, 2020) was translated from English into Romanian using the forward-backward translation design (Hambleton, Yu \& Slater 1999). Minor corrections to the translations were made based on the back-translation process. For the care for others moral foundation, the forwardbackward translated version of the measure is available on Moral Foundations Questionnaire official Internet page (https://moralfoundations.org/questionnaires/). For measuring altruistic behaviour, the self-report altruism scale distinguished by the recipient (SRAS-DR-RO) validated on Romanian sample was used (Marcu \& Bucuță, 2016).

The short form of the Critical Consciousness Scale (CCS-S) (Rapa, Bolding \& Jamil, 2020) was used to evaluate critical motivation. The sub-scale critical motivation, composed of four items, was extracted. Participants were requested to evaluate their answers on a six-point Likert scale ranging from $1=$ strongly disagree to $6=$ strongly agree. The range selected for this scale allows a more nuanced understanding of the pathways of critical consciousness development and highlights the interrelationships between critical consciousness dimensions (Heberle et al., 2020; Rapa, Bolding \& Jamil, 2020). For the three sub-scales, Cronbach's alpha coefficient is .63.

To assess altruistic behaviour, the validated version of the self-report altruism scale distinguished by the recipient (SRAS-DR-RO) was used (Marcu \& Bucuță, 2016). This scale was formulated on evolutionary grounds and evaluates altruism in terms of the frequency of altruistic behaviours towards various receivers such as family members, friends and strangers in everyday life (Oda et al., 2013). It consists of 21 items rated on a five-point Likert scale from 1 (never) to 5 (very often). Cronbach's alpha value of this measure is .83.

Care for others moral foundation was measured using the designated sub-scale from the Moral Foundations Questionnaire (MFQ-S) (Graham et al., 2011). This instrument was translated into Romanian by a researcher and back-translated into English by a professional translator (available at www.moralfoundations.org). This measure has been used extensively in cross-cultural research and demonstrates good validity and reliability properties (Iurino \& Saucier, 2018). The harm/care moral foundation measure includes three items assessing the perceived relevance of moral concerns and three items assessing agreement with moral judgments. Participants rated the relevance items on a Likert-type scale ranging from 0 (not at all relevant) to 5 (extremely relevant) and the judgment items on the same six-point Likert-type scale ranging from 0 (strongly disagree) to 5 (strongly agree). After eliminating the last two items referring to moral judgement, Cronbach's alpha for the care foundation was .54, which is considered acceptable considering the low number of items (Hinton et al., 2004). 


\section{Results}

\section{Descriptive statistics and Pearson correlation analyses}

In Table 1, the information regarding the means, standard deviations, Cronbach's alpha reliability index and correlations between all the variables examined in the present research is displayed. Critical motivation showed significant correlations with altruistic behaviour and care for others in the investigated directions. Specifically, critical motivation is positively associated with altruistic behaviour $(r=.18, p<.001)$ and care for others $(r=.30, p<.001)$.

Table 2. Descriptive statistics, Pearson correlations and reliability estimates between the studied variables

\begin{tabular}{lrrr}
\hline \multicolumn{1}{c}{ Variables } & 1 & 2 & \multicolumn{1}{c}{3} \\
\hline 1. Altruistic behaviour & .89 & & \\
2. Critical motivation & $.188^{* *}$ & .63 & $307^{* *}$ \\
3. Care for others & $.183^{* *}$ & $.188^{* *}$ & .54 \\
Mean & 86.95 & 18.86 & 18.90 \\
SD & & & \\
\hline
\end{tabular}

Note: ${ }^{* *} \mathrm{p} \leq .01$. Alpha Cronbach's coefficients are shown on the diagonal

\section{Care for others moral foundation as mediator in the relationship between critical motivation and altruistic behaviour}

The PROCESS 3.5 macro for IBM SPSS version 24 for Windows was used to test the hypothesised simple mediation model (Hayes, 2013). This method allows testing mediators and provides bootstrap confidence intervals (CIs) for the indirect effects (Hayes, 2013) by building bootstrap-based confidence intervals to test the statistical significance of mediation effects in a nonparametric and reduced biased manner (Preacher \& Hayes, 2004). In the present study, a mediation analysis was conducted using regression and 5,000 resamples (to estimate 95\% confidence intervals) in order to investigate whether the effect of critical motivation on altruistic behaviour was mediated by the care for other moral foundation.

The analysis confirmed a significant total effect of critical motivation on altruistic behaviour (c) and this relationship remained significant when the effects of care for others were taken into account ( $\left.c^{\prime}\right)$. This analysis confirmed a significant total effect of 
critical motivation (c) and this relationship is significant when the effect of care for others is considered ( $\left.c^{\prime}\right)$. This analysis revealed that critical motivation was significantly positively related to care for others (a) and care for others was significantly positively related to altruistic behaviour when controlling for critical motivation (b). Results showed that care for others mediated the effect of critical motivation on altruistic behaviour as indicated by a significant indirect effect ( $\mathrm{B}=.16, \mathrm{SE}=.07,95 \%$ BCa CI: .028, .333), such that the high levels of critical motivation predicted altruistic behaviour; this was directly emphasised by higher levels of care for others. The $95 \%$ confidence interval did not include the value zero, indicating the significance of the mediating effects. Figure 2 illustrates the mediating effects.

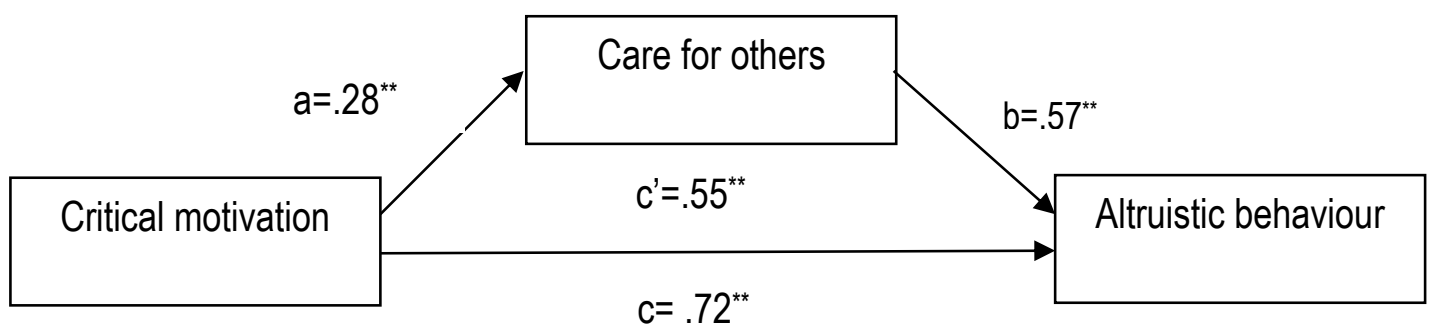

Figure 2. Mediation model depicting the mediating effect of care for others on the relation between critical motivation and altruistic behaviour. Unstandardized coefficients are presented. Note: ${ }^{*} p \leq .05 ;^{* *} p \leq .01$

\section{Conclusions}

Investigating youths' beliefs, attitudes and behaviour presents a unique perspective over social development processes that will reflect their future behaviour (Shildrick, Blackman \& MacDonald, 2009). Young individuals must be seen as valuable community resources that can influence through their participation several social domains. Developing certain skills in youth such as critical consciousness, critical analysis and leadership can help them develop an active role in the community (Hancock, 1994). Critical consciousness was associated with prosocial actions and civic engagement (Flanagan \& Christens, 2011; Diemer \& Li, 2011). Recent research has not yet examined which specific component of critical consciousness impacts social action. Therefore, acknowledging the association between critical consciousness and social action, this research study tested a simple mediation model of the relationships between critical motivation, care for others and altruistic behaviour. The mediating role of care for others in the relationship between critical motivation and altruistic behaviour was studied.

Our results showed that care for others moral foundation mediates the relationship between critical motivation and altruistic behaviour. This suggests that when young people display critical motivation, they are likely to provide care and protection towards others; consequently, this has a positive impact on altruistic behaviour. Our conclusions 
are consistent with former assumptions from the social area showing that critical consciousness, given critical motivation, leads to social action (Freire, 1973).

The present study shows some limitations that should be mentioned. The research did not focus on a wide spectrum of social actions and was solely limited to altruistic behaviour. Hence, future studies should examine the mediating role of caring for others having, as a result, a wide range of social behaviours. Further, personality trait variables should be taken into account to fully understand the process through which critical consciousness predicts social action. Another limitation relates to the structure of the research sample, which consists mainly of women participants. This reduces considerably the degree of generalisation that can be made from the present results. Thus, future inquiries should examine larger and more gender-balanced samples. Nonetheless, our results are in line with previous assumptions that focus on the path from critical consciousness to social action and add to the existing literature by providing some information concerning the link between critical motivation and altruistic behaviour in youth.

\section{References}

Ajaps, S. O., \& Obiagu, A. N. (2020). Increasing civic engagement through civic education: A Critical Consciousness Theory Perspective. Journal of Culture and Values in Education, 4(1), 64-87. DOI: 10.46303/jcve.2020.2.

Chronister, K. M., \& McWhirter, E. H. (2006). An experimental examination of two career interventions for battered women. Journal of Counseling Psychology, 53(2), 151. DOI: 10.1037/0022-0167.53.2.151.

Diemer, M. A., \& Blustein, D. L. (2006). Critical consciousness and career development among urban youth. Journal of vocational behavior, 68(2), 220-232. DOI: 10.1016/j.jvb.2005.07.001.

Diemer, M. A., \& Li, C. H. (2011). Critical consciousness development and political participation among marginalized youth. Child development, 82(6), 1815-1833. DOI: 10.1111/j.1467-8624.2011.01650.x.

Diemer, M. A., \& Rapa, L. J. (2016). Unraveling the complexity of critical consciousness, political efficacy, and political action among marginalized adolescents. Child development,87(1), 221-238. DOI: 10.1111/cdev.12446.

Diemer, M. A., Rapa, L. J., Voight, A. M., \& McWhirter, E. H. (2016). Critical consciousness: A developmental approach to addressing marginalization and oppression. Child Development Perspectives, 10(4), pp. 216221. DOI: $10.1111 /$ cdep.12193.

Finn, J. L., \& Checkoway, B. (1998). Young people as competent community builders: A challenge to social work. Social work, 43(4), 335-345. DOI: 10.1093/sw/43.4.335.

Flanagan, C. A., \& Christens, B. D. (2011). Youth civic development: Historical context and emerging issues. New Directions for Child and Adolescent Development, 2011(134), 1-9. DOI: 10.1002/cd.307.

Flanagan, C. A., Cumsille, P., Gill, S., \& Gallay, L. S. (2007). School and community climates and civic commitments: Patterns for ethnic minority and majority students. Journal of Educational Psychology, 99(2), 421-431. DOI: 10.1037/0022-0663.99.2.421.

Furlong, A., \& Cartmel, F. (2006). Young people and social change. UK: McGraw-Hill Education.

Freire, P. (1973). Extension or Communication. New York: The Seabury Press.

Freire, P. (2005). Education for critical consciousness. New York, NY: Continuum.

Ginwright, S., \& James, T. (2002). From assets to agents of change: Social justice, organizing, and youth development. New directions for youth development, 2002(96), 27-46. DOI: 10.1002/yd.25.

Giroux, H. A. (1983). Theory and resistance in education: A pedagogy for the opposition. South Hadley: Bergin \& Garvey. 
Godfrey, E. B., \& Burson, E. (2018). Interrogating the intersections: How intersectional perspectives can inform developmental scholarship on critical consciousness. New directions for child and adolescent development, 2018(161), 17-38. DOI: 10.1002/cad.20246.

Godfrey, E. B., Burson, E. L., Yanisch, T. M., Hughes, D., \& Way, N. (2019). A bitter pill to swallow? Patterns of critical consciousness and socioemotional and academic well-being in early adolescence. Developmental psychology, 55(3), 525. DOI: 10.1037/dev0000558.

Graham, J., Nosek, B. A., Haidt, J., Iyer, R., Koleva, S., \& Ditto, P. H. (2011). Mapping the moral domain. Journal of personality and social psychology, 101(2), 366. DOI:10.1037/a0021847.

Hambleton, R. K., Yu, J., \& Slater, S. C. (1999). Fieldtest of the ITC Guidelines for adapting educational and psychological tests. European Journal of Psychological Assessment, 15(3), 270-276. DOI: 10.1027//10155759.15.3.270.

Hancock, M. (1994). Collaboration for youth development: Youth action programming. National Civic Review, 83(2), 139-145. DOI: 10.1002/ncr.4100830207.

Hayes, A. (2013). Introduction to mediation, moderation, and conditional process analysis: A regression-based approach (1st ed.). New York: The Guilford Press.

Hinton, P., D., Hinton, P. R., McMurray, I., \& Brownlow, C. (2004). SPSS explained. Routledge.

Hope, E. C. (2016). Preparing to participate: The role of youth social responsibility and political efficacy on civic engagement for Black early adolescents. Child Indicators Research, 9: 609-630. DOI: 10.1007/s12187-0159331-5.

Iurino, K., \& Saucier, G. (2020). Testing measurement invariance of the Moral Foundations Questionnaire across 27 countries. Assessment, 27(2): 365-372. DOI: 10.1177/1073191118817916.

Jemal, A. (2017). Critical consciousness: A critique and critical analysis of the literature. The Urban Review, 49(4): 602-626. DOI: 10.1007/s11256-017-0411-3.

Kirshner, B., \& Ginwright, S. (2012). Youth organizing as a developmental context for African American and Latino adolescents. Child Development Perspectives, 6(3), 288-294. DOI: 10.1111/j.17508606.2012.00243.x.

Lai, F. H., Siu, A. M., \& Shek, D. T. (2015). Individual and social predictors of prosocial behavior among Chinese adolescents in Hong Kong. Frontiers in pediatrics, 3, 39. DOI: 10.3389/fped.2015.00039.

Marcu, G., \& Bucuță, M. D. (2016). Adaptation and validation of Japanese Self-Report Altruism Scale Distinguished by the Recipient (SRAS-DR) on Romanian population. Working Papers. Retrieved from: https://www.researchgate.net/publication/279914119.

Mustakova-Possardt, E. (2004). Education for critical moral consciousness. Journal of Moral Education, 33(3), 245-269. DOI: 10.1080/0305724042000733046.

Oda, R., Dai, M., Niwa, Y., Ihobe, H., Kiyonari, T., Takeda, M., \& Kai, H. (2013). Self-report altruism scale distinguished by the recipient (SRAS-DR): Validity and reliability. Shinrigaku kenkyu: The Japanese journal of psychology, 84(1), 28-36. DOI: DOI: 10.4992/jjpsy.84.28.

Patterson, M. M., Fite, P. J., Zucker, J. K., \& Abel, M. R. (2021). Critical consciousness among rural adolescents: the roles of school connection and positive relationships with teachers. Social Psychology of Education, 1-18. DOI: $10.1007 / \mathrm{s} 11218-021-09613-2$.

Preacher, K. J., \& Hayes, A. F. (2004). SPSS and SAS procedures for estimating indirect effects in simple mediation models. Behavior research methods, instruments, \& computers, 36(4), 717-731. DOI: 10.3758/BF03206553.

Rapa, L. J., Bolding, C. W., \& Jamil, F. M. (2020). Development and initial validation of the short critical consciousness scale (CCS-S).Journal of Applied Developmental Psychology, 70, 101164. DOI: 10.1016/j.appdev.2020.101164.

Rushton, J. P. (1982). Altruism and society: A social-learning perspective. Ethics, 92, 425-446. Retrieved from: https://www.jstor.org/stable/2380730.

Rushton, J. P., Bons, T. A., \& Hur, Y-M. (2008). The genetics and evolution of a general factor of personality. Journal of Research in Personality, 42, 1173-1185. DOI: 10.1016/j.jrp.2009.01.005. 
Tyler, C. P., Olsen, S. G., Geldhof, G. J., \& Bowers, E. P. (2020). Critical consciousness in late adolescence: Understanding if, how, and why youth act. Journal of Applied Developmental Psychology, 70, 101165.s. DOI: 10.1016/j.appdev.2020.101165.

Seider, S., Clark, S., \& Graves, D. (2020). The development of critical consciousness and its relation to academic achievement in adolescents of color. Child Development, 91(2), e451-e474. DOI: 10.1111/cdev.13262.

Shildrick, T., Blackman, S., \& MacDonald, R. (2009). Young people, class and place. Journal of youth studies, 12(5), 457-465. DOI: $10.1080 / 13676260903114136$.

Watts, R. J., \& Hipolito-Delgado, C. P. (2015). Thinking ourselves to liberation?: Advancing sociopolitical action in critical consciousness. The Urban Review, 47(5), 847-867. DOI: 10.1007/s11256-015-0341-x.

Watts, R. J., Diemer, M. A., \& Voight, A. M. (2011). Critical consciousness: Current status and future directions. New directions for child and adolescent development, 2011(134), 43-57. DOI: 10.1002/cd.310.

Youniss, J., \& Yates, M. (1997). Community service and social responsibility in youth: Theory and policy. Chicago: University of Chicago Press. 